\title{
THE CHRONIC KIDNEY DISEASE RISK ANALYSIS IN PATIENTS WITH ARTERIAL HYPERTENSION AND COEXISTENT HYPERURICEMIA
}

DOI: 10.36740/WLek202105127

\author{
Olha M. Chernatska, Liudmyla N. Prystupa, Hanna A. Fadieieva, Alina V. Liashenko, Oksana S. Pogorielova, \\ Nataliia 0. Opolonska \\ INTERNAL MEDICINE DEPARTMENT WITH RESPIRATORY MEDICINE CENTER, SUMY STATE UNIVERSITY MEDICAL INSTITUTE, SUMY, UKRAINE
}

\begin{abstract}
The aim: Is the analysis of chronic kidney disease risk in patients with arterial hypertension and coexistent hyperuricemia. Materials and methods: We observed 40 patients with arterial hypertension and coexistent hyperuricemia (I group), 35 - with arterial hypertension (II group) and 30 practically healthy people (control). The duration of hypertension was $4,3 \pm 2,31$ years and $4,0 \pm 2,11$ years $(p=0,9247)$ for l and II group respectively, of hyperuricemia $-4,1 \pm 0,35$ years for I group. Categories of albuminuria (A1, A2, A3) and glomerular filtration rate (G1, G2, G3A, G3B, G4, G5) were determined in all observed patients. Clinical, anthropometric, biochemical, immunoassay, statistical (SPSS 21, Graph Pad) methods were used.

Results: The categories of albuminuria and glomerular filtration rate in patients from the I group demonstrated that A1G1 was confirmed in 3 persons, A1G2 - 5, A2G1 - 7, $A 2 G 2-20, A 1 G 3 A-1, A 1 G 3 B-1, A 2 G 3 A-2, A 2 G 3 B-1$. Among patients from the ll group category A1G1 was defined in 7, A1G2 - 2, A2G1 - 16, A2G2 - 10 persons. The percent of low chronic kidney disease risk was on 5,7 \% higher in hypertensive persons comparable with comorbid persons. High and very high risk was confirmed in $10 \%$ persons from I group and nobody from the II group.

Conclusions: Chronic kidney disease risk is increased in patients with arterial hypertension and coexistent hyperuricemia. This indicates an association between elevated uric acid levels and chronic kidney disease progression.
\end{abstract}

KEY WORDS: chronic kidney disease risk, arterial hypertension, hyperuricemia

\section{INTRODUCTION}

High blood pressure (BP) remains the leading cause of death, accounting for 10,4 million deaths per year. More than $50 \%$ of hypertensive patients have additional cardiovascular risk factors. The most common of them have diabetes $(15 \%-20 \%)$, lipid profile disorders (30\%), overweight or obesity ( $40 \%)$, hyperuricemia $(25 \%)$ and metabolic syndrome (40\%) [1].

Hypertension is a major risk factor for the development and progression of albuminuria and chronic kidney disease (CKD). A lower glomerular filtration rate (GFR) is associated with resistant, masked hypertension, and elevated nighttime BP values [2].

Multiple studies have demonstrated an independent association between hyperuricemia and arterial hypertension $(\mathrm{AH})$ [3]. Most urates are therefore readily filtered by the glomeruli, although up to $90 \%$ then may be reabsorbed [4]. The CKD risk evaluation in patients with $\mathrm{AH}$ and coexistent hyperuricemia is not clearly demonstrated today.

\section{THE AIM}

The aim is the CKD risk analysis in hypertensive persons with coexistent increased uric acid levels.

\section{MATERIALS AND METHODS}

The study was done during 2018-2019 years. We recruited 75 patients with $\mathrm{AH}$ in the our study. They were divided in two groups according to the level of uric acid in the blood. Patients from I group $(\mathrm{n}=40)$ had AH and coexistent hyperuricemia; II $(\mathrm{n}=35)-$ AH. Practically healthy people $(n=30)$ observed because of preventive medical examinations were belonged to the control.

Patients were enrolled in the study after informed consent obtained in accordance with the Helsinki Declaration of the World Medical Association on the Ethical Principles of Scientific and Medical Research. The study was approved by the Bioethics Committee for experimental and clinical studies at Sumy State University Medical Institute.

Persons with $\mathrm{AH}$ and hyperuricemia were $52,4 \pm 0,69$ years old, $\mathrm{AH}-54,1 \pm 0,61$ years old $(\mathrm{p}=0,0725)$, practically healthy people $-53,3 \pm 0,4$ years old $(\mathrm{p}=0,3045)$. The percent of males were 70 in the I group, 68,6 in the II group, 70 in the control. The level of systolic BP were 146,4 $\pm 5,38 \mathrm{mmHg}, 144,7 \pm 7,07$ $\mathrm{mmHg}(\mathrm{p}=0,8467), 120,8 \pm 6,48 \mathrm{mmHg}(\mathrm{p}=0,0032)$; diastolic BP - 94,8 $\pm 6,05 \mathrm{mmHg}, 93,9 \pm 5,93 \mathrm{mmHg}(\mathrm{p}=0,9162)$, $80,1 \pm 2,6 \mathrm{mmHg}(\mathrm{p}=0,0495)$ respectively for patients from the I, II group and practically healthy people. The duration of AH were 4,3 $\pm 2,31$ years old and 4,0 $\pm 2,11$ years old $(\mathrm{p}=0,9247)$; uric acid levels $-401,6 \pm 3,93 \mathrm{mcmol} / \mathrm{l}$ and 
Table I. Indicators for GFR calculation by Cockroft-Gault test in observed patients

\begin{tabular}{|c|c|c|c|c|}
\hline Indicator & $\begin{array}{l}\text { I group } \\
(n=40)\end{array}$ & $\begin{array}{l}\text { II group } \\
(n=35)\end{array}$ & $\begin{array}{l}\text { control } \\
(n=30)\end{array}$ & $\mathbf{p}$ \\
\hline Serum creatinine, $\mathrm{mcmol} / \mathrm{l}$ & $0,1 \pm 0,02$ & $0,08 \pm 0,003$ & $0,07 \pm 0,001$ & $\begin{array}{l}\mathrm{p}_{1}=0,3571 \\
\mathrm{p}_{2}=0,1994 \\
\mathrm{p}_{3}=0,0043\end{array}$ \\
\hline body mass, kg & $75,9 \pm 1,79$ & $69,9 \pm 1,4$ & $60,2 \pm 0,1$ & $\begin{array}{l}\mathrm{p}_{1}=0,0117 \\
\mathrm{p}_{2}<0,0001 \\
\mathrm{p}_{3}<0,0001\end{array}$ \\
\hline age, years & $52,4 \pm 0,69$ & $54,1 \pm 0,61$ & $53,3 \pm 0,4$ & $\begin{array}{l}\mathrm{p}_{1}=0,0725 \\
\mathrm{p}_{2}=0,3045 \\
\mathrm{p}_{3}=0,2941\end{array}$ \\
\hline
\end{tabular}

Notes: 1. $p$ - the significance of differences between the indicators of the I and II groups; $2 . n$ - number of persons;

Table II. Indicators of kidney function in observed patients

\begin{tabular}{|c|c|c|c|c|}
\hline Indicator & $\begin{array}{l}\text { I group } \\
(n=40)\end{array}$ & $\begin{array}{l}\text { II group } \\
(\mathbf{n}=35)\end{array}$ & $\begin{array}{l}\text { control } \\
(n=30)\end{array}$ & $\mathbf{p}$ \\
\hline Albuminuria, $\mathrm{Mr} / \mathrm{I}$ & $91,3 \pm 12,28$ & $34,1 \pm 2,51$ & 0 & $\mathrm{p}_{1}<0,0001$ \\
\hline glomerular filtration rate, $\mathrm{ml} / \mathrm{min}$ & $81,4 \pm 2,65$ & $103,5 \pm 4,64$ & $92,7 \pm 2,4$ & $\begin{array}{l}p_{1}<0,0001 \\
p_{2}=0,0032 \\
p_{3}=0,0534\end{array}$ \\
\hline
\end{tabular}

Notes: 1. $p$ - the significance of differences between the indicators of the I and II groups; $2 . n$ - number of patients

Table III. Categories of albuminuria and glomerular filtration rate

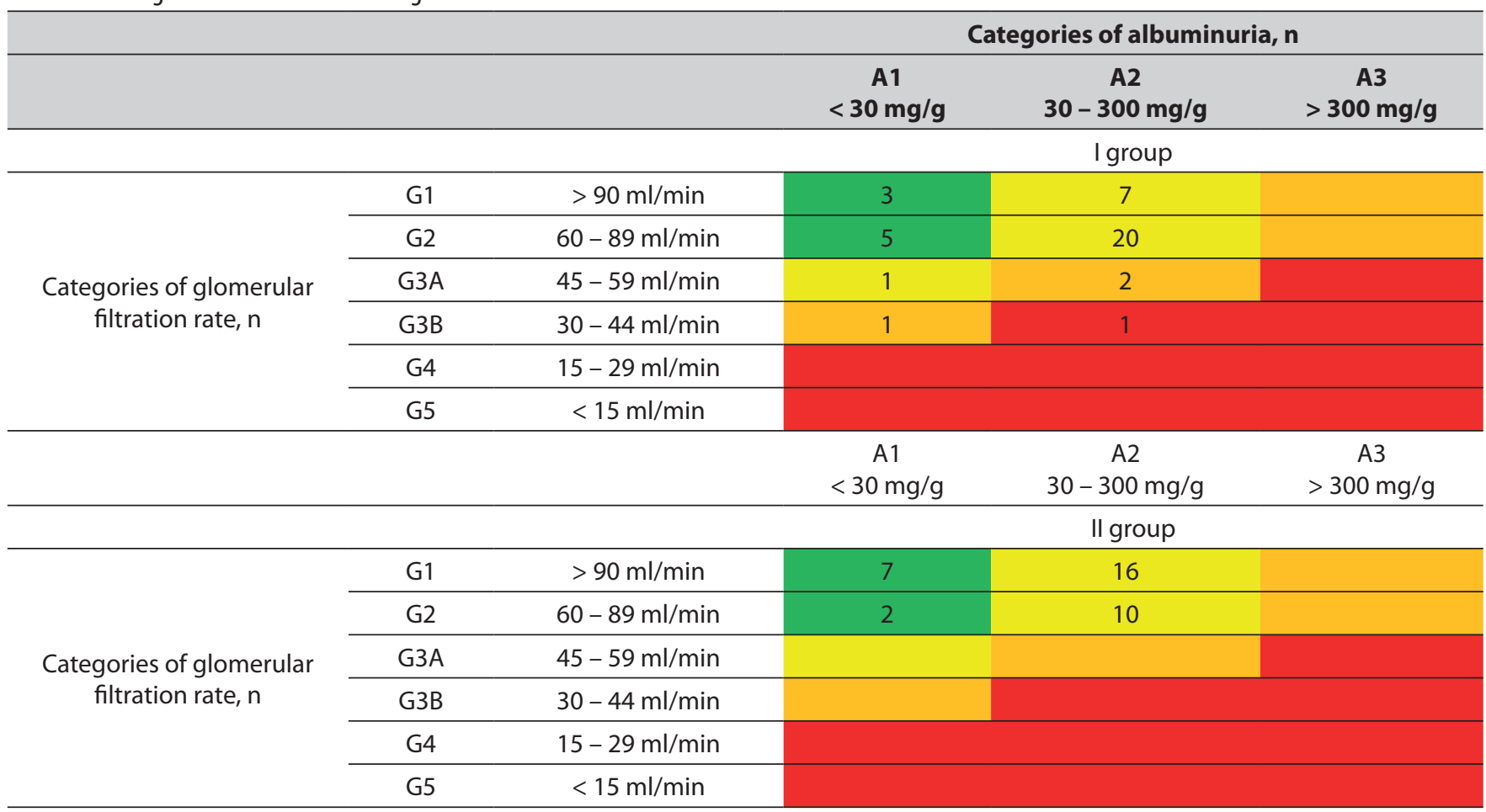

Notes: $n$ - quantity of persons; green color - low risk ofCKD; yellow color - moderate risk of CKD; orange color - high risk ofCKD; red color - very high risk of CKD.

$304,5 \pm 4,95 \mathrm{mcmol} / \mathrm{l}$ respectively for hypertensive persons with and without hyperuricemia. The duration of increased uric acid levels was 4,1 $\pm 0,35$ years for patients from the I group.

Hyperuricemia was determined by European League Against Rheumatism (EULAR, 2016 p.) if the uric acid level was more than $360 \mathrm{mcmol} / \mathrm{l}$ (6 mg/dl) [5]. Asymptomatic hyperuricemia was the coexistent pathology in hypertensive patients.
Albuminuria, GFR reduction, and left ventricular (LV) hypertrophy are objective signs of target organs damage for $\mathrm{AH}[1]$. These indicators were analyzed in hypertensive patients with and without hyperuricemia.

Categories of albuminuria (A1, A2, A3) and GFR (G1, G2, G3A, G3B, G4, G5) were determined by "Kidney Disease: Improving Global Outcomes" (KDIGO, 2012) [6]. 


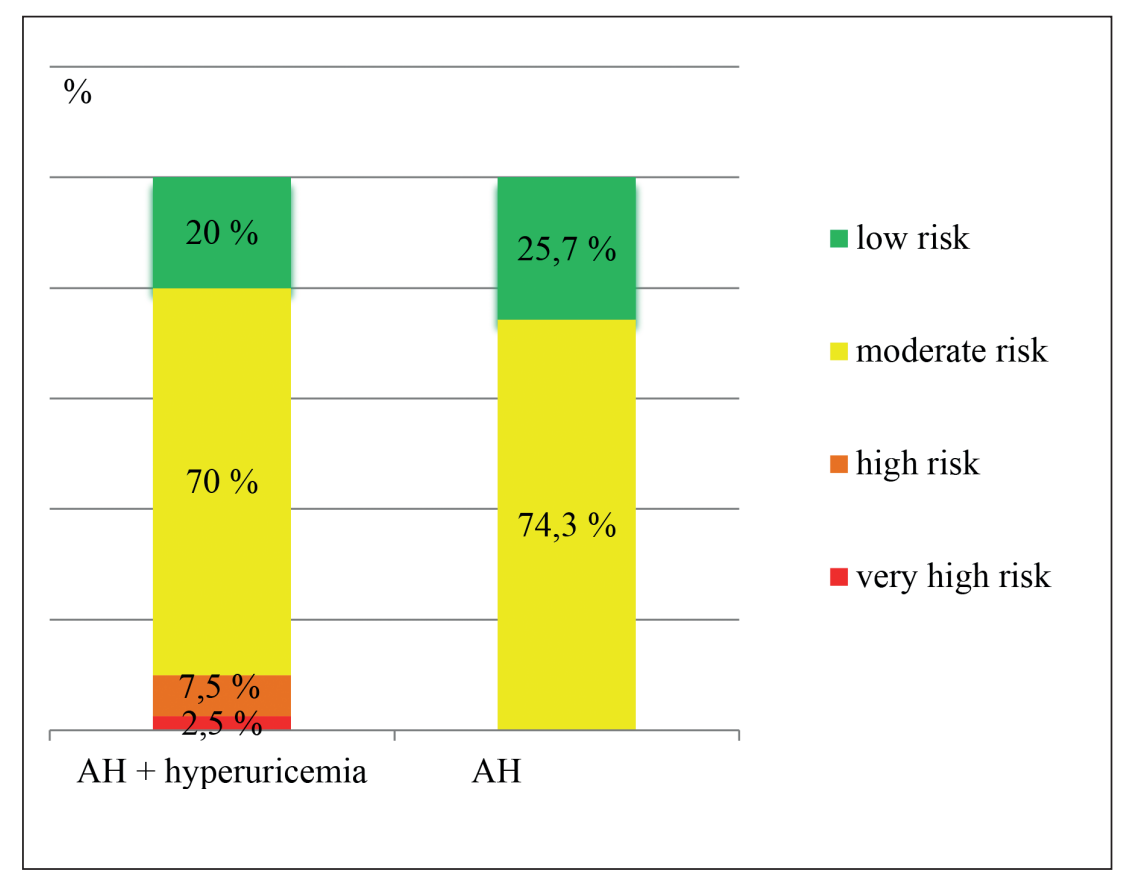

Fig. 1. Assessment the risk of chronic kidney disease in the I and II group
The exclusion criteria were patient's refusal from participation, stroke, acute coronary syndrome, GFR $<30 \mathrm{ml} /$ min., malignancies, viral hepatitis, acute inflammatory process, diabetes mellitus type 1 and 2 , intolerance to glucose, pheochromocytoma, and atrial fibrillation.

All observed patients were comparable by age with predominance of men.

The significant difference between the level of systolic and diastolic BP were absent in patients from the I and II group ( $\mathrm{p}=0,8467 ; \mathrm{p}=0,9171)$.

The duration of $\mathrm{AH}$ was respectively $(4,3 \pm 2,31)$ and $(4,0 \pm 2,11)$ year $(\mathrm{p}=0,9247)$ for patients with $\mathrm{AH}$ and coexistent hyperuricemia comparable with hypertensive persons.

Firstly we determined AH in all persons. Hyperuricemia was the coexistent pathology.

We use clinical, anthropometric, biochemical, statistical methods and immunoassay, collected history, made the physical examination of all participants.

Measurement of height $(\mathrm{m})$ was made by centimeter tape; weight $(\mathrm{kg})$ - by electronic scales. Body surface area was calculated by Mosteller formula as square root of the height $(\mathrm{cm})$ multiplied by the weight $(\mathrm{kg})$ divided by 3600 [7].

Serum uric acid level was observed by enzymatic photocolorimetry. The highest level of uricemia is associated with increased color intensity of the product resulted by the reaction with uricase [8]. GFR was calculated by CockroftGault formula after the determination of serum creatinine.

Albuminuria concentration was determined by one-stage competitive enzyme immunoassay.

All results were analyzed by SPSS 21 and GraphPad.

This research was adopted by the Ethics Committee of Sumy State University, Sumy, Ukraine. Research was conducted keeping to the main issues of the Convention of the Council of Europe on Human Rights and Biomedicine of Declaration of Helsinki of the World Medical Association on the ethical principles of conducting medical research involving human beings (1975, with further amendments, including version of 2000) and Order of Ukrainian Ministry of Health № 690 on 23.09.2009.

\section{RESULTS AND DISCUSSION}

The GFR was compared in persons from I and II group for the assessment of the influence of hyperuricemia on the functional condition of kidney in hypertensive patients.

We estimated all indicators for GFR calculation by Cockroft-Gault test (table I) and of kidney function (table II).

The analyses of kidney function disorders showed that the level of albuminuria was significantly higher $(\mathrm{p}<$ $0,0001)$, GFR - lower $(p<0,0001)$ in patients from the I group compared with the II.

The mean level of GFR was $(81,4 \pm 2,65) \mathrm{ml} / \mathrm{min}$ in persons with $\mathrm{AH}$, coexistent hyperuricemia and confirmed the II degree of CKD. The mean level of GFR was (103,5 \pm $4,64) \mathrm{ml} / \mathrm{min}$ in hypertensive patients and confirmed the I degree of CKD.

The categories of albuminuria and GFR for CKD risk assessment were determined in patients with $\mathrm{AH}$ and coexistent hyperuricemia and hypertensive persons (table III).

The assessment of categories of albuminuria and GFR in patients from the I group clearly demonstrated that A1G1 was confirmed in $3, \mathrm{~A} 1 \mathrm{G} 2-5, \mathrm{~A} 2 \mathrm{G} 1-7, \mathrm{~A} 2 \mathrm{G} 2-20$, A1G3A - 1, A1G3B - 1, A2G3A - 2, A2G3B - 1 .

The assessment of categories of albuminuria and GFR in patients from the II group indicated that A1G1 was defined in $7, \mathrm{~A} 1 \mathrm{G} 2-2, \mathrm{~A} 2 \mathrm{G} 1$ - 16, A2G2 - 10.

The CKD risk was analyzed in all observed patients (figure I).

The percent of patients with low CKD risk was on 5,7\% higher in hypertensive persons comparable with comorbid 
persons with $\mathrm{AH}$ and hyperuricemia. High and very high CKD risk was confirmed in $10 \%$ persons from I group and nobody from the II group.

Finally, the CKD risk increased in hypertensive patients with coexistent hyperuricemia.

Our finding showed that the level of albuminuria was significantly higher $(\mathrm{p}<0,0001)$, GFR - lower $(\mathrm{p}<0,0001)$ in patients from the I group compared with the II. A lot of researches had similar results. On the one hand, elevated serum uric acid level is recognized as a biomarker for cardiovascular disease, such as $\mathrm{AH}$, on the other hand, as for renal morbidity. Han and colleagues recently sought to address the temporal relationship between hyperuricemia and hypertension $[3,9]$. The relationship with CKD is complicated by the fact that reduced GFR is, in turn, associated with hyperuricemia secondary to reduced renal clearance. In experimental models, this has been somewhat counter-balanced by a compensatory increase in intestinal excretion of uric acid in the setting of renal insufficiency $[3,10,11]$.

It has been clearly demonstrated that hyperuricemia is associated with progression of CKD [12]. Furthermore, we have analyzed the categories of albuminuria and GFR in patients with $\mathrm{AH}$ and coexistent hyperuricemia.

\section{CONCLUSION}

Chronic kidney disease risk is increased in patients with arterial hypertension and coexistent hyperuricemia. This indicates an association between elevated uric acid levels and chronic kidney disease progression.

\section{REFERENCES}

1. 2020 International Society of Hypertension Global Hypertension Practice Guidelines. Hypertension. 2020;75(6):1334-57. doi:10.1161/ HYPERTENSIONAHA.120.15026.

2. Drawz P.E., Alper A.B., Anderson A.H. et al. Masked hypertension and elevated nighttime blood pressure in CKD: prevalence and association with target organ damage. Clin J Am Soc Nephrol. 2016;11:642-52. doi: 10.2215/CJN.08530815.

3. Stewart J.D., Langlois V., Noone D. Hyperuricemia and Hypertension: Links and Risks. Integr Blood Press Control. 2019;12:43-62. doi: 10.2147/ IBPC.S184685.

4. Bobulescu I.A., Moe 0.W. Renal transport of uric acid: evolving concepts and uncertainties. Adv Chronic Kidney Dis. 2012;19(6):358-371. doi: 10.1053/j.ackd.2012.07.009.

5. 2016 updated EULAR evidence-based recommendations for the management of gout. Ann Rheum Dis. 2016;10:1-14. doi:10.1136/ annrheumdis-2016-209707.

6. Levin A., Stevens P.E. Summary of KDIGO 2012 CKD Guideline: behind the scenes, need for guidance, and a framework for moving forward. Kidney International. 2013;85:49-61; doi:10.1038/ki.2013.444.
7. Mosteller R.D. Simplified calculation of body-surface area. N Engl J Med. 1987;317(17):1098. doi: 10.1056/NEJM198710223171717.

8. Fossati P., Prencipe L., Berti G. Use of 3,5-dichloro-2hydroxybenzenesulfonicacid/4-aminophenazone chromogenic system in direct enzymic assay of uric acid in serum and urine. Clin Chem. 1980;26(2):227-31.

9. Han T., Meng X., Shan R. etal. Temporal relationship between hyperuricemia and obesity, and its association with future risk of type 2 diabetes. Int J Obes. 2018;42(7):1336-44. doi: 10.1038/541366-018-0074-5.

10. Yano H., Tamura Y., Kobayashi K. et al. Uric acid transporter ABCG2 is increased in the intestine of the $5 / 6$ nephrectomy rat model of chronic kidney disease. Clin Exp Nephrol. 2014;18(1):50-55. doi: 10.1007/ s10157-013-0806-8.

11. Vaziri N.D., Freel R.W., Hatch M. Effect of chronic experimental renal insufficiency on urate metabolism. J Am Soc Nephrol. 1995;6(4):1313-17.

12. Galán I., Goicoechea M., Quiroga B. et al. Hyperuricemia is associated with progression of chronic kidney disease in patients with reduced functioning kidney mass. Nefrologia. 2018;38(1):73-78. doi:10.1016/.j.nefro.2017.04.006.

01164004046 "Diseases of the internal organs: predictors of development, optimization, diagnosis, treatment and prevention». The work was not financed by any funds or organizations.

\section{ORCID and contributionship:}

Olha M. Chernatska: 0000-0001-9093-6862 ${ }^{F D}$

Liudmyla N. Prystupa: 0000-0002-6454-9831 ${ }^{\mathrm{A}}$

Hanna A. Fadieieva: 0000-0003-3056-5793 ${ }^{\mathrm{C}}$

Alina V. Liashenko: 0000-0002-7172-2858 ${ }^{B}$

Oksana S. Pogorielova: 0000-0003-4077-8637 ${ }^{E}$

Nataliia O. Opolonska: 0000-0003-1965-156X ${ }^{E}$

\section{Conflict of interest:}

The Authors declare no conflict of interest.

\section{CORRESPONDING AUTHOR Olha M. Chernatska \\ Sumy state university \\ 2 Rimsky-Korsakov St., 40000 Sumy, Ukraine \\ tel: +380502089987 \\ e-mail: chernatskaya@ukr.net}

Received: 11.12 .2020

Accepted: 01.04.2021

A - Work concept and design, B - Data collection and analysis, C - Responsibility for statistical analysis,
D-Writing the article, E-Critical review, F - Final approval of the article 